\title{
Sistemas Setoriais de Inovação em Países Emergentes: O Software na Índia e no Brasil em Perspectiva Comparada
}

\author{
Pedro Martins ${ }^{1}$, Manuel Gonzalo ${ }^{2}$ e Marina Szapiro ${ }^{3}$
}

\begin{abstract}
Resumo
O presente trabalho analisa os Sistemas Setoriais de Inovação (SSI) em software no Brasil e na Índia, dois países emergentes onde o desenvolvimento de software se constitui numa atividade econômica de grande relevância. O objetivo é entender as trajetórias e elementos-chave de cada SSI, e sugerir reflexões voltadas ao caso brasileiro. Evidencia-se que os modelos de desenvolvimento do setor de software são divergentes, principalmente no que diz: 1) à natureza da demanda como fonte de conhecimento, 2) ao timing, a intensidade e o escopo das políticas públicas, e 3) aos modelos de negócio, processos de gestão e níveis de visibilidade das firmas. A partir desta análise, argumenta-se que os fatores do sucesso de cada SSI são fortemente idiossincráticos e não são facilmente emuláveis em outros países emergentes. Ainda assim, o artigo sugere uma série de insights voltados ao desenvolvimento do setor de software no Brasil.
\end{abstract}

Palavras-chave: Software, Sistemas Setoriais de Inovação, Índia, Brasil

\begin{abstract}
This article analyses the Sectoral Systems of Innovation (SSI) of software in two emerging countries, Brazil and India, where the software development constitutes a very relevant economic activity. Its aim is to comprehend the trajectory and key elements of each SSI, while pursuing insights to the Brazilian case. It is clear that the SSI differ in their path of development, particularly regarding: 1) the nature of the demand as a knowledge source, 2) the timing, intensity and scope of the public policies and 3) the business models, management processes and firm visibility. From this analysis, we argue that the success factors are highly idiosyncratic and difficult to copy in other developing economies. In spite of that, we conclude with some insights to the enhancement of software sector in Brazil.
\end{abstract}

Keywords: Software, Sectoral Systems of Innovation, India, Brazil

Área ABEIN: 4.3 (Sistemas de inovação - nacional, regional, setorial, tecnológico)

Classificação Journal Economic Literature (JEL): 057 (Economic Development, Innovation, Technological Change, and Growth - Comparative Studies of Countries)

\footnotetext{
${ }^{1}$ IE/UFRJ - pedrosbarbosamartins@ @mail.com

${ }^{2}$ Pesquisador ProDem, IDEI/UNGS; RedeSist, IE/UFRJ - gonzalo.manolo@ gmail.com

${ }_{3}$ Professora IE/UFRJ, pesquisadora RedeSist, IE/UFRJ - marina@ie.ufrj.br
} 


\section{Introdução}

É difícil imaginar outra atividade produtiva que esteja mais disseminada no cotidiano moderno do que o desenvolvimento de software. No uso constante de smartphones por parte significativa da população mundial na última década, na rápida difusão da Internet desde os anos 1990 e na revolução do computador pessoal do final da década de 1980, por exemplo, o software teve papel central e relevância crescente. Do ponto de vista econômico, os sistemas de informação surgiram no contexto da revolução da microeletrônica e tiveram impactos consideráveis na estrutura produtiva mundial. Fora os efeitos diretos da indústria, o software assume papel central nos processos de inovação de praticamente todos os setores produtivos da economia, e é relevante no aprendizado interno e entre organizações (Schware, 1992; Quinn et al., 1997). O mercado mundial de Tecnologias da Informação (TI) atinge hoje valores anuais acima dos US\$ 2 trilhões (ABES, 2017), e o software, como já apontado, é a base de todo esse mercado4.

A ubiquidade e o impacto do software nas mais diversas atividades econômicas transformaram este setor em importante objeto de análise na literatura e foco de política. De fato, todos os países desenvolvidos apresentam algum grau de competências domésticas em software e políticas públicas que procuram alavancar seus efeitos no resto da estrutura produtiva (Roselino, 2006). Entre os países emergentes, os primeiros casos de sucesso na indústria de software foram relacionados a economias que tiveram êxito na inserção externa e na criação de uma base de exportação voltada aos principais mercados, em especial os EUA.

Destaca-se entre estes países a Índia, que em 2005 alcançou a liderança mundial na exportação de serviços de software (Mani, 2014), posição mantida até hoje, e que demonstra sinais claros de estar ativamente buscando espaços de maior valor agregado na indústria.

O Brasil, por outro lado, parece ter seguido um caminho alternativo. Ainda que o setor de software brasileiro figure entre os dez maiores do mundo há pelo menos uma década (Veloso et al., 2003; ABES, 2017), sua base de exportação permanece substancialmente reduzida quando comparada a países como a Índia. Esta configuração sugere que a trajetória voltada à inserção no mercado internacional não é a única viável para o desenvolvimento virtuoso da indústria de software em países emergentes.

O objetivo deste trabalho é, portanto, analisar os Sistemas Setoriais de Inovação (SSI) em software do Brasil e da Índia, a fim de entender suas trajetórias e elementos-chave específicos, destacando suas semelhanças e diferenças, além de sugerir algumas reflexões orientadas ao caso brasileiro. Em termos metodológicos, este trabalho está baseado na revisão da literatura sobre os SSI da Índia e do Brasil e na consulta de fontes primárias de informação. Em particular, no caso da Índia, foram realizadas em torno de oito entrevistas com policy-makers, empreendedores e pesquisadores da cidade de Bangalore, em agosto de 201655. No caso da análise do SSI em software brasileiro, foram utilizadas fontes secundárias.

A seguir, a seção 2 define a base teórica para a análise subsequente. As seções 3 e 4 apresentam, respectivamente, os SSI em software na Índia e no Brasil. Na seção 5 se faz uma revisão comparada das duas análises, identificando as principais diferenças entre os dois SSI. A seção 6 apresenta brevemente algumas reflexões e possíveis aprendizados da experiência indiana para o Brasil.

\section{Sistemas Setoriais de Inovação em Países Emergentes}

\subsection{Inovação sistêmica}

A visão sistêmica da inovação surge do debate efetuado nos anos 1970 e 80 em torno da abordagem econômica neoschumpeteriana. Este debate, por sua vez, origina-se do descontentamento de alguns economistas com o tratamento neoclássico dado aos processos de transformação tecnológica. Enquanto na economia tradicional a inovação constitui apenas um choque exógeno e pontual, cujo único efeito, após um

\footnotetext{
${ }^{4}$ Neste trabalho, opta-se por segmentar o mercado de software em duas categorias principais, que evidenciam os dois modelos de negócio gerais existentes na indústria: o software produto e os serviços de software. Entre os serviços de software, é possível também segmentar ademais as atividades entre serviços de baixo valor agregado e serviços de alto valor agregado, categorização que será usada em algumas análises deste trabalho.

${ }^{5}$ Ver Gonzalo (2018)
} 
processo de ajustamento por preços, é o estabelecimento de um novo equilíbrio, estas abordagens assumem que o processo inovativo é fundamental e inerente ao funcionamento do capitalismo moderno (Lundvall, 1992). Mesmo com o advento das teorias neoclássicas de crescimento, que passaram a incorporar o progresso técnico em sua análise, o foco nas condições de equilíbrio contraria a visão defendida por Schumpeter (1962) de que o capitalismo é, fundamentalmente, um motor de progresso econômico e tecnológico.

Influenciados pela obra de Schumpeter, autores como Lundvall, Freeman e Edquist, na Europa, assim como Nelson e Winter ${ }^{6}$, nos EUA, trabalharam a partir da década de 70 em novas perspectivas econômicas sobre a inovação, dando atenção especial ao papel que a informação e o conhecimento exercem na economia (Lundvall, 1992; Cassiolato e Lastres, 2005; Sharif, 2005).

É neste contexto intelectual que nasce o conceito de sistemas nacionais de inovação (SNI), recorte original e mais geral da abordagem. O primeiro uso explícito do termo é creditado ao trabalho de Freeman sobre o Japão (Freeman, 1987), sendo posteriormente aprofundado em novos estudos (como Dosi et al., 1988; Lundvall, 1992; Nelson, 1993; Edquist, 1997). Outras perspectivas de SI se seguiram, focando em diferentes recortes ou objetos. Destacam-se, além da análise setorial utilizada no presente trabalho, o recorte regional (Cooke et al.,1997; Braczyk et al.; 1998; Asheim e Isaksen, 2002), o recorte local (De la Mothe e Paquet, 1998) e a abordagem de sistemas tecnológicos (Carlsson e Stankiewitz, 1991).

Para a visão dos SI, o conhecimento é o principal recurso econômico. O aprendizado, processo pelo qual se acumula e se recombina conhecimento, é fundamentalmente interativo e social, inseparável do contexto cultural e institucional de onde ocorre, e indispensável ao processo de inovação. As firmas, portanto, não inovam isoladamente, e suas ações são influenciadas por instituições. Destes fundamentos segue-se que a inovação não é, como retrata a economia tradicional, um fenômeno pontual e externo à economia, mas sim um processo endógeno, não-linear e cumulativo, fortemente ligado às instituições, políticas e manifestações culturais particulares ao espaço em que está inserido (Lundvall, 1992).

\subsection{Os sistemas setoriais de inovação em países emergentes}

Malerba (2002) identifica duas principais tradições da análise setorial: aquela relacionada à literatura da economia industrial e outra ligada à literatura evolucionista e da inovação sistêmica. Ainda que a economia industrial ofereça um instrumental conceitual relevante para analisar diferentes setores, o enfoque dos sistemas setoriais de inovação (SSI) representa um framework multidimensional e integrado para complementar o estudo setorial.

A abordagem de SSI inclui na análise outros agentes de mercado, como usuários e fornecedores, além de agentes externos ao mercado, como universidades e agências governamentais. Foca em boa medida nas interações entre firmas e os atores externos ao mercado, e passa também a considerar os limites setoriais como dinâmicos e em constante transformação. Essa nova visão, desenvolvida principalmente por Malerba no final dos anos 1990, se baseia extensamente nas abordagens dos sistemas de inovação (SI) e da economia evolucionista.

Malerba (2005) apresenta uma definição concisa e completa de sistema setorial de inovação:

Sectoral systems of innovation have a knowledge base, technologies, inputs and a (potential or existing) demand. They are composed of a set of agents carrying out market and non-market interactions for the creation, development and diffusion of new sectoral products. A sectoral system undergoes processes of change and transformation through the coevolution of its various elements. (Malerba, 2005, p. 66)

\footnotetext{
${ }^{6}$ Nelson e Winter desenvolveram no início dos anos 1980 a abordagem econômica evolucionista, que serve como importante influência para o desenvolvimento posterior da abordagem dos sistemas setoriais de inovação. Os autores partiram de uma análise onde firmas possuem racionalidade limitada e dependem da interação com outros agentes econômicos, e cujas rotinas são reproduzidas e aprimoradas de acordo com sua memória organizacional. Em geral, as escolhas de uma firma se diferenciam das escolhas das demais, e tendem a ser selecionadas - ou descartadas - de acordo com o ambiente econômico em que são tomadas.
} 
Assim, é possível identificar três elementos-chave de um sistema setorial: 1) a sua base de conhecimento e tecnologia, 2) seus agentes e redes, e 3) as instituições que o afetam direta ou indiretamente.

É importante ressaltar que, quanto a estímulos e efeitos, os sistemas setoriais de inovação ultrapassam o domínio das fronteiras nacionais. Entretanto, as particularidades de um sistema nacional de inovação podem tanto reforçar quanto atenuar os efeitos multidimensionais de um sistema setorial. Países com instituições, políticas e agentes integrados em um sistema nacional podem se beneficiar de características globais ou transnacionais presentes em um setor, quando comparados a países que não contam com esses fatores. Ao usar o conceito de SSI, portanto, é necessário levar em consideração as diferenças profundas entre países desenvolvidos e em desenvolvimento em relação a contextos institucionais, comportamentos e competências das firmas, e outros elementos-chave setoriais.

Em comparação aos países centrais, muitos países emergentes contam com instituições significativamente menos desenvolvidas e, em alguns casos, ausentes. Joseph (2009) argumenta que essas deficiências podem ter um impacto importante na performance de seus sistemas setoriais respectivos. Os efeitos da fraqueza institucional em países emergentes podem ser discernidos na fraca interação entre firmas privadas e centros de pesquisa públicos, na dependência de spillovers de tecnologia estrangeira, assim como nos esforços domésticos de P\&D limitados por evasão de capital humano. Mesmo quando um país emergente se destaca em um setor, a falta de instituições fortes pode levar ao enfraquecimento de outros setores complementares, cruciais para o desenvolvimento sustentável do primeiro.

\section{SSI em software na Índia}

O setor de software indiano é frequentemente analisado como um dos principais exemplos entre países emergentes de inserção global exitosa em atividades intensivas em conhecimento. A indústria, que soma a produção de software produto, software embarcado e serviços, viu sua receita subir de US\$ 0,83 bilhões em 1994-95, para mais de US\$ 140 bilhões em 2016. De acordo com NASSCOM (2017), o software é responsável hoje por mais de 7\% do PIB indiano. Em 2016, mais de 3,7 milhões de profissionais eram empregados pelo setor, em comparação aos 160.000 empregados em 1996 (NASSCOM, 2017).

Essa performance é derivada das exportações. O crescimento anual composto (CAGR) das exportações de software da Índia ultrapassou 40\% nos anos 1990, e foi pouco abaixo de $25 \%$ na primeira década do século XXI, apesar dos impactos causados pela crise de 2008 (Joseph, 2014). Desde os 2000, como pode ser observado na Figura 3.1, as exportações de software indiano continuaram crescendo até representar em 2015 25\% das exportações totais da Índia e $67 \%$ das exportações de serviços.

Figura 3.1: Exportações de software indiano sobre o total de exportações e sobre o total de exportações de serviços. 2000-2015.

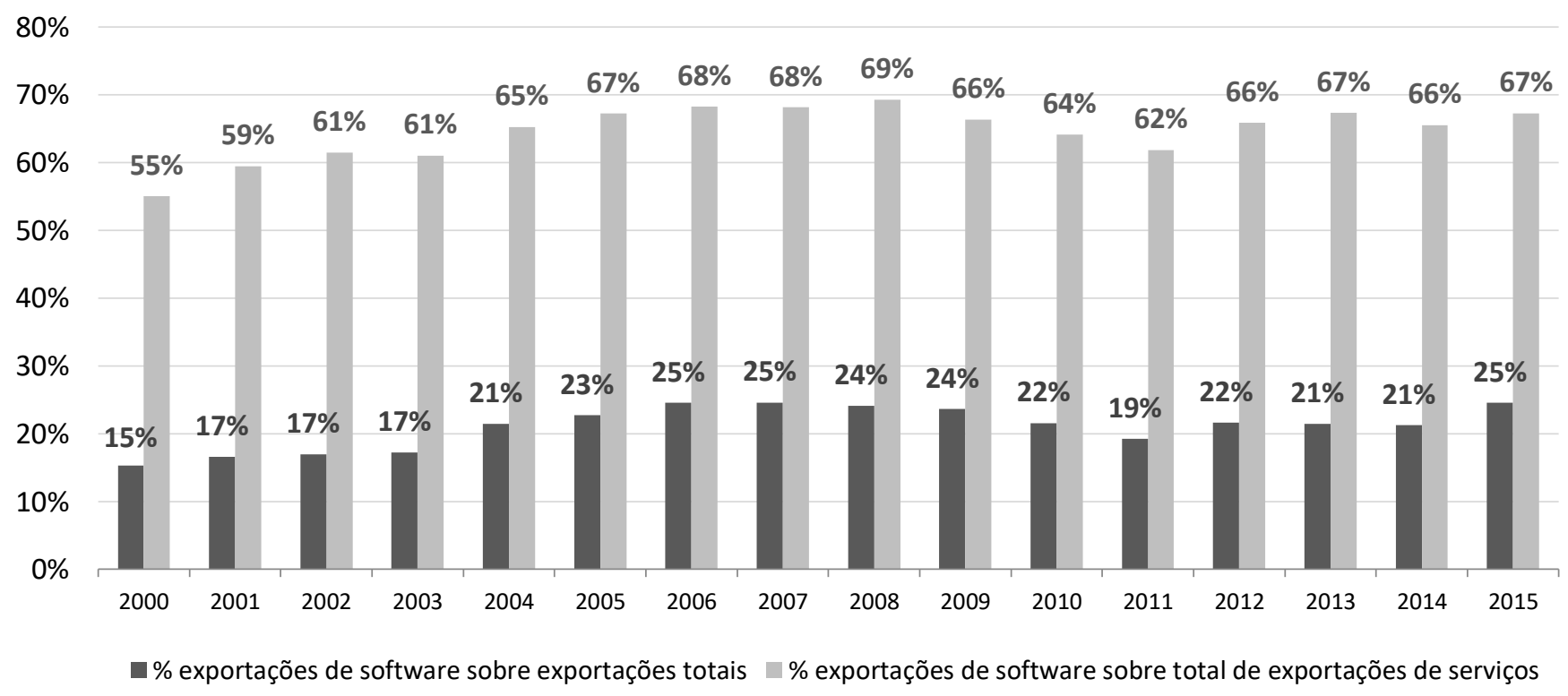

Fonte: Banco Mundial. 
Contudo, é importante ressaltar que a inserção da Índia no mercado de software se deu principalmente na exportação de atividades de baixo valor agregado, tais como codificação, manutenção e testes. Ao longo das duas últimas décadas, estes serviços responderam por quase $70 \%$ das exportações de software, enquanto atividades de maior valor agregado, como o software produto e os serviços de engenharia, apresentaram participação mais modesta, em torno de 5\% (Mani, 2014).

Ainda assim, a Índia aproveitou o potencial apresentado pelo software para impulsionar se inserir em um mercado internacional de alta tecnologia, e também de que procura alcançar posições mais altas nas cadeias de valor das indústrias de TI. As firmas de software indianas direcionam suas operações e exportações para mais de 170 países, e contam em sua base de clientes com as maiores empresas transnacionais do mundo. A credibilidade do setor de software indiano é exemplificada pelos processos de takeover de firmas de TI estrangeiras pelas firmas indianas, assim como a difusão de inovações organizacionais e gerenciais da Índia para fora (Joseph, 2009), discutidos na subseção 4.3.1.

\subsection{Evolução do setor}

No início da década de 1970, a saída da $\operatorname{IBM}^{7}$ da Índia possibilitou uma série de spin-off indianas criadas pelos ex-funcionários da multinacional que conformou uma primeira semente de empresas nacionais para o desenvolvimento da indústria da computação na Índia (Gonzalo e Cassiolato, 2017). Ao constatar o potencial do software enquanto indústria, sua relevância estratégica em termos militares e seu peso nas contas externas, o governo indiano atuou para desenvolver as exportações do setor a partir do Departamento de Eletrônica (DOE) (Athreye, 2005). Até a metade da década de 1980, entretanto, a estratégia adotada era de prover complementariedade à indústria doméstica de hardware, em um contexto de forte regulamentação externa.

Com o espaço aberto para a produção doméstica de hardware e para novas empresas estrangeiras de computação, cresceu substancialmente a necessidade de conversão de software entre diferentes sistemas de computadores, assim como de manutenção dos códigos obsoletos (legacy codes), especialmente dos mainframes da IBM. Além das várias firmas indianas que se especializaram nestes serviços, o governo indiano comprou a IBM Índia, passando a se chamar Computer Maintenance Company (CMC), que acumulou suas competências.

Ao final da década de 1980, os mercados de computação foram marcados pela queda dos preços de hardware e pela transição dos mainframes para a arquitetura client-server. O impacto da nova tecnologia para as firmas de software se deu de duas maneiras. Em primeiro lugar, diminuiu as barreiras e os custos da indústria por ser mais flexível e menos intensiva em capital do que a tecnologia anterior. Em segundo, gerou uma crescente demanda por software personalizado. Especificamente para a Índia, as competências criadas em torno da manutenção de sistemas obsoletos (legacy systems) como os mainframes, assim como de conversão entre linguagens e arquiteturas diferentes, tornou-se uma vantagem importante no mercado de software do período (Athreye, 2005). A política de software de 1986 substituiu então a estratégia anterior de complementar a indústria doméstica de hardware, e possibilitou o desenvolvimento independente do setor de software.

A ampliação do outsourcing norte-americano a partir dos anos 1980 configura um fator crucial para a performance do software indiano, já que, sem a contínua demanda mundial pelos serviços de software, as competências de firmas indianas seriam insuficientes para impulsionar o setor, cuja atividade doméstica era ainda muito reduzida (Gonzalo e Kantis, 2017). Além da disponibilidade de profissionais de língua inglesa na Índia e da presença de indianos na cena empreendedora norte-americana, a diferença de 12 horas entre o fuso dos dois países contribuiu para a interação exitosa em torno dos serviços de software, já que o dia de trabalho indiano é naturalmente estendido pelo dos EUA.

\footnotetext{
${ }^{7}$ A saída da IBM do mercado indiano aconteceu como resposta ao Foreign Exchange Regulation Act (FERA), que obrigava a empresa a diluir suas participações de capital próprio para $40 \%$.
} 
Nos anos 90, dois fenômenos contribuíram para um substancial crescimento da demanda mundial por software, o problema Y2K e o boom das empresas de internet. Com a aproximação do novo milênio, firmas precisavam garantir que seus programas e aplicativos não teriam problemas técnicos relacionados à nova numeração anual. Assim, a Índia atuou como a principal provedora de soluções $\mathrm{Y} 2 \mathrm{~K}$, já que era o único país com mão-de-obra extensa o suficiente para o trabalho massivo de reescrever um número elevado de linhas de código (Lee et al., 2014).

Ao longo do boom da Internet, indivíduos indianos se posicionaram como importantes empreendedores, gestores técnicos e gerentes, principalmente nos EUA. Muitos, devido ao sucesso nos seus respectivos empreendimentos, se transformaram em financiadores de capital de risco, primeiro no Vale do Silício e depois na Índia (Gonzalo e Kantis, 2017). A indústria de serviços de TI indiana certamente lucrou com essa ampliação de credibilidade. Mesmo com o estouro da bolha dotcom ${ }^{8}$, o setor continuou crescendo, agora amparado pelo outsourcing das empresas norte-americanas que se viam obrigadas a cortar custos de serviços e P\&D internos (Lee et al., 2014).

A Índia alcança a liderança internacional desse mercado em 2005, posição que conseguiu expandir e que mantém até hoje (Mani, 2014). A liderança inicial dos EUA, o primeiro player e principal mercado de software, foi substituída pela Irlanda na década de 90 devido ao aumento dos custos de se produzir domesticamente. Entre os anos de 1995 e 2005, a partir de esforços de offshoring, as diversas filiais de transnacionais estrangeiras instaladas no país expandiram substancialmente suas exportações. A concentração da produção fora das firmas domésticas, entretanto, enfraqueceu a liderança irlandesa.

Nos anos 2000, a disponibilidade de mão-de-obra qualificada a preços competitivos na Índia, aliada ao acúmulo de competências e a produtividade das firmas indianas na área, provocaram em 2005 a nova transição de liderança no mercado (Mani, 2014).

É importante ressaltar que esta transição se deu em um contexto institucional e de política econômica diferente daquele dos anos 1970 e 80. A crise indiana da balança de pagamentos em 1991 levou à adoção de regulações mais liberais, incluindo a substituição do FERA e um afrouxamento das barreiras ao Investimento Direto Externo (Gonzalo e Cassiolato, 2017). Coincidindo com a aceleração da demanda mundial por software, o período de liberalização experimentou um grande afluxo de transnacionais estrangeiras para a Índia, incluindo a volta da IBM (1992), a chegada da Oracle (1993), da Cisco (1995) e de outras grandes corporações mundiais de TI.

Mesmo neste período, políticas ativas do governo indiano proveram suporte ao setor de software, como a já citada política de 1986 e a iniciativa dos Software Technology Parks of India (STPI) de 1988. Ao longo dos anos 1990, os impostos sobre a importação de software foram reduzidos e isenções fiscais foram oferecidas a firmas do setor.

A credibilidade das competências indianas junto ao mercado internacional reforçou as oportunidades de entrada no setor de software. Entretanto, a concentração das atividades em núcleos geográficos voltados para a exportação, como Bangalore, limitou as ligações verticais com o mercado doméstico de software e o resto da economia indiana (Joseph, 2014; D’Costa, 2003).

O início dos anos 2000 foi marcado por uma consolidação do setor de software na Índia, com a adoção de grandes projetos de outsourcing pelas firmas líderes domésticas (Athreye, 2005).

\subsection{Elementos-chave do sistema setorial}

\subsubsection{Agentes}

A disponibilidade de mão-de-obra qualificada a baixo custo e de língua inglesa (Heeks, 1996) foi o fator determinante para a entrada da Índia como um player competitivo no mercado internacional de software, no contexto da crescente demanda mundial provocada pelo processo de outsourcing norte-

\footnotetext{
${ }^{8}$ Desde o final da década de 1990, o crescente uso e adoção da Internet levou à criação de novas empresas e mercados baseados na rede mundial. A bolha dotcom, fruto de acentuada especulação em torno destes empreendimentos, estourou no ano 2000, e teve impacto considerável nos setores de TI.
} 
americano. Desta maneira, destacam-se como agentes fundamentais no desenvolvimento do software na Índia os profissionais de TI, entre engenheiros, programadores e técnicos. Esta força de trabalho foi fruto de extensas políticas educacionais adotadas pelo governo a partir dos anos 1970, em particular na criação de institutos técnicos e carreiras terciárias orientadas ao desenvolvimento do setor (Heeks, 1996; Joseph, 2009). Por exemplo, para aumentar a qualidade e nivelar os cursos oferecidos nas áreas de TI, o DOE passou a oferecer também certificações e a padronizá-los. Criou ainda novas instituições como o National Institute of Information Technology, com participação da indústria, para fazer frente à escassez de profissionais durante aceleração da demanda de software na década de 1990. Neste sentido, além dos investimentos públicos, as maiores empresas indianas de software também fizeram esforços de capacitação e treinamento interno (Joseph, 2009; Lee et al., 2014).

O papel dos empreendedores indianos em identificar as oportunidades no setor de software, principalmente aquelas de exportação, é bem documentado na literatura (Athreye, 2005; Joseph, 2009; Mani, 2014). Já na década de 1970, com a saída da IBM do mercado indiano, ex-funcionários da gigante norte-americana criaram empresas empreendedoras de computação, ajudando a manter viva a demanda pelas competências relacionadas à programação e ao software (Athreye, 2005). Algumas das firmas mais dinâmicas do setor, como a Infosys e a HCL, que mais tarde se consolidariam como líderes mundiais, foram criadas por empreendedores indianos com experiência anterior nas áreas de TI, sendo tão proeminentes entre as firmas líderes quanto as firmas tradicionais. Em 2001, por exemplo, firmas empreendedoras eram responsáveis por quase $37 \%$ das vendas de TI (Athreye, 2005).

Como enfatizado em Gonzalo e Kantis (2017), os indianos não-residentes foram agentes centrais no desenvolvimento do setor, atuando em oportunidades de negócios nos Estados Unidos para firmas indiana, em empreendimentos na Índia e no financiamento de risco da indústria. Estes indivíduos formaram um substancial movimento migratório, reconhecido como a Diáspora Indiana, que começou com a emigração de estudantes e profissionais à procura de melhores condições de emprego a partir do pós-guerra. Muitos destes indianos chegaram aos EUA, formaram-se como engenheiros e técnicos, e se inseriram nos inícios do desenvolvimento do Valle do Silício na Califórnia desde a década de 1960.0 posicionamento dos indianos no ecossistema empreendedor do Vale do Silício possibilitou nos anos 1980 e 90 a capitalização das oportunidades de outsourcing por parte das firmas indianas, redirecionando para a Índia o conhecimento adquirido sobre o mercado e o financiamento necessário para empreendimentos de software. Em outros casos, indianos-americanos voltaram à Índia, em um movimento contrário à diáspora anterior, para criar novas firmas de software (Mani, 2014; Gonzalo e Kantis, 2017).

Ademais, o principal fator para a manutenção da liderança indiana nos serviços de software foi a concentração de firmas domésticas no setor (Mani, 2014). Ao contrário da Irlanda, onde a liderança nos serviços de TI entre 1995 e 2005 foi mantida graças às operações das transnacionais estrangeiras instaladas no país, as firmas domésticas dominam o mercado de software indiano. Ainda que a presença de firmas estrangeiras, em especial norte-americanas, seja visível no setor de software da Índia, metade das dez maiores exportadoras atuando no país era indiana em 2015-16, inclusive as três principais (Electronics and Software Export Promotion Council, 2017).

Embora a política ativa do governo indiano tenha sido essencial para o desenvolvimento do setor de software, as firmas e o empreendedorismo doméstico tiveram importante parcela nesse esforço. Mesmo sob a restrição de gargalos de infraestrutura física (principalmente nas telecomunicações), práticas burocráticas e certas políticas externas desfavoráveis, como impostos sobre a importação de software e compromissos de exportação a serem pagos ao governo, firmas e empreendedores conseguiram assegurar sucessos no setor de software. Uma vez alcançado e demonstrado o potencial do setor, o governo passou também a responder com medidas de suporte (Athreye, 2005; Mani, 2014).

Por fim, destacam-se também as associações industriais, agentes fundamentais para o sucesso do software na Índia. A NASSCOM, a principal e mais proativa, foi criada em 1988 e hoje conta com mais de 2,200 firmas, que são responsáveis por $90 \%$ das receitas no setor. Os dois principais papéis da NASSCOM foram a intermediação entre a indústria e o governo indiano, e a projeção da imagem da Índia para o mercado internacional de TI e a certificação de processos e firmas (Joseph, 2009). Além disso, a associação 
realizou esforços para facilitar a emissão de vistos para países desenvolvidos em nome de profissionais da indústria, assim como para combater a pirataria de software no país.

\subsubsection{Políticas públicas}

A evolução da política econômica indiana da segunda metade do século XX pode ser dividida em dois grandes períodos (Gonzalo e Cassiolato, 2017). Do pós-guerra até o início dos anos 1990, a Índia viveu um período de forte participação e regulação estatal. A partir da crise externa de 1990 e a implementação da New Economic Policy (NEP) em 1991, se iniciaram uma série de políticas de liberalização, principalmente no que diz respeito ao comércio, ao investimento estrangeiro direito e às restrições à entrada de empresas nos diferentes setores da economia.

Como já mencionado, o governo indiano tratou a indústria do software como um complemento à indústria doméstica de hardware até 1986. Apenas em 1986, com a nova política de software, impostos previamente adotados ao software foram removidos e o setor pôde crescer independente da indústria de hardware. Alguns problemas persistiam, como os impostos sobre importação de software e os compromissos de exportação a serem pagos ao governo, que favoreciam as firmas de maior porte (Athreye, 2005).

O setor se beneficiou de políticas ativas de inovação, em especial a iniciativa dos Software Technology Parks (STPs) de 1988. Focando nos gargalos de infraestrutura em telecomunicações, a iniciativa facilitou o acesso a essas redes para firmas de pequeno porte que exportavam software. Os STPs também proporcionavam outros serviços e estruturas que diminuíram o custo de produção e criaram centros regionais voltados para a atividade de exportação de software. Em particular, a criação dos STPs possibilitou o desenvolvimento de competências domésticas de software em polos específicos para esta atividade, proporcionando economias de aglomeração.

Alem disso, como destacado em Joseph (2014, 2009), o papel dos Indian Institute of Technology na formação de engenheiros e pessoal qualificado foi central. Em particular, o desenvolvimento de cursos específicos para programadores e técnicos em software foi uma política diretamente orientada para o desenvolvimento da industria.

Ao longo dos anos 1990, o setor de software indiano recebeu novos incentivos. A liberalização levou ao fim dos compromissos de exportação nos STPs, a redução de impostos sobre a importação de software (1992-95) e isenção do imposto de renda na exportação de software (1993-99).

\subsection{Perspectivas e novas oportunidades paro o software indiano}

O setor de software indiano, ainda que tradicionalmente concentrado na exportação de serviços de menor valor agregado, vem demonstrando sinais de ascensão nas cadeias globais de valor, principalmente a partir dos anos 2000 (Lee et al, 2014). Firmas indianas têm presença hoje em áreas intensivas em conhecimento, como design de microchips e serviços de $\mathrm{P} \& \mathrm{D}$, se afastando dos serviços de Business Process Outsourcing (como call-centers e aplicações internas aos negócios dos clientes) e criando competências em Knowledge Process Outsourcing (que incluem serviços de alto valor agregado, como serviços de pesquisa e engenharia).

Um indicador atual deste processo é o crescimento do setor de software produto. Firmas indianas líderes como a Infosys e a Tata Consultancy Services (TCS) introduziram importantes produtos principalmente voltados ao mercado interno. Ao mesmo tempo, a Internet facilitou a criação de lideranças e a distribuição de produtos até entre firmas pequenas. Entre 2005 e 2011, a participação do software produto cresceu quase 8 pontos percentuais entre as vendas domésticas de software (Joseph, 2014).

O surgimento de transnacionais indianas de TI e o processo de takeover de outras firmas do setor é outro indicativo das transformações ocorridas na indústria do software na Índia. A TCS é uma das empresas mais ativas neste processo, tendo comprado a indiana CMC em 2002, ganhando acesso a uma base maior do mercado doméstico, assim como a australiana Financial Network Service (2005) e a suíça TKS 
Teknosoft (2006), adquirindo importantes competências em serviços financeiros para montar seu portfólio de soluções, entre outras aquisições (Lee et al., 2014).

O software também vem crescendo enquanto participação no PIB indiano. Da contribuição de 1,85\% em 2000-01, o software passou a ser responsável por 4,7\% em 2010-11 (Governo da Índia, 2012 13), e hoje responde por mais de 7\% (NASSCOM, 2017). Neste sentido, a National Policy on IT de 2011 reforça a ideia de um setor de software indiano mais voltado para o mercado doméstico, e central no papel de desenvolvimento das áreas ainda atrasadas do país. Sem se afastar muito da sua posição no mercado internacional, a política também foca no desenvolvimento de soluções de TI para o mundo, tendo como objetivo elevar a Índia à posição de principal centro e destino global para serviços de TI até 2020 (Joseph, 2014).

As políticas orientadas ao setor têm recebido uma nova ênfase nos últimos anos. Entre outras iniciativas, destaca-se o National e-Governance Plan, instituído em 2006, para prover serviços públicos para a sociedade indiana de maneira local e a baixo custo. O plano é focado nas comunidades menos favorecidas, com o objetivo de tornar serviços públicos vitais mais acessíveis e de promover o empreendedorismo rural (Joseph, 2014). Ligadas ao plano de e-governance, as iniciativas Digital India e Unified Mobile Application for New-age Governance (UMANG). A primeira iniciativa procura expandir a infraestrutura de comunicações e o acesso à Internet, a fim de garantir o acesso eletrônico aos serviços governamentais. A segunda procura reunir uma larga parte destes serviços em um único aplicativo móvel, com disponibilidade em diversas línguas indianas.

Iniciativas domésticas de empreendedorismo focadas em startups também floresceram nos últimos anos. A Startup India, lançada em 2016, é um exemplo claro. O projeto visa construir um ecossistema que fomente a inovação e a criação de startups, simplificando normas e regulações, fornecendo apoio e incentivos de financiamento, e promovendo interações entre a indústria e a pesquisa acadêmica. A NASSCOM também criou a 10.000 Startups, iniciada em 2013, que procura reunir incubadoras, aceleradoras, mentores, investidores, experts da indústria e outros agentes.

\section{SSI em software no Brasil}

O setor de software no Brasil apresenta um desenvolvimento nitidamente distinto daquele observado no caso indiano. Com um nível de exportação substancialmente menor, o crescimento do software brasileiro esteve historicamente ancorado à demanda interna. Ainda assim, em 2001 a indústria já figurava entre as dez maiores do mundo, com um faturamento de US\$ 7,7 bilhões e mais de 150,000 trabalhadores empregados, representando 1,5\% do PIB brasileiro (Veloso et al., 2003). A Associação Brasileira das Empresas de Software (ABES) estima que o faturamento da indústria em 2016 foi de US\$ 19,4 bilhões, contando software produto e serviços, e que o crescimento anual composto entre os anos de 2006 e 2016 tenha sido de aproximadamente 10\% (Figura 4.1) (ABES, 2017).

Figura 4.1: Crescimento do software produto e serviço no Brasil (2006-2016)

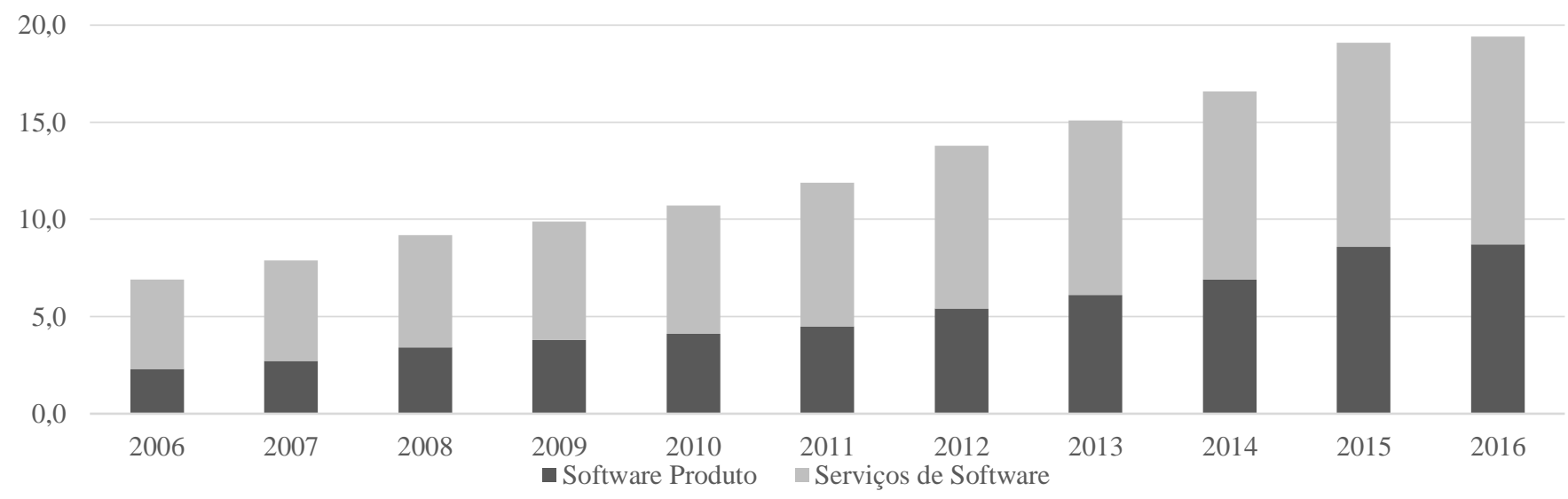

Fonte: ABES (2017). Faturamento em US\$ bilhões, dólar constante de R \$ 3,335/US\$. 
A performance externa do software no Brasil é de difícil mensuração, devido à inexistência de estudos consistentes e de metodologia clara sobre a comercialização do software no exterior, aliada à inerente dificuldade em mensurar transações via Internet (que hoje representam parcela importante do comércio de software) e à predominância nos estudos brasileiros de estimativas amostrais (Roselino, 2006). Tendo em mente essas limitações, o valor comumente apontado na literatura para o ano de 2001, por exemplo, é de US\$ 100 milhões, apenas 1,3\% do total da indústria e muito abaixo dos US\$ 6,2 bilhões exportados pela Índia no mesmo ano (Veloso et al., 2003). Em 2017, a ABES estimou a exportação brasileira de software e serviços relacionados em menos de US\$ 700 milhões, o que representa aproximadamente 3,5\% do total faturado pela indústria (ABES, 2017). Tal valor encontra-se significativamente abaixo dos US\$ 108 bilhões exportados pela Índia (NASSCOM, 2017).

Mesmo que não se tenha uma imagem exata da posição e evolução do software brasileiro no mercado internacional, fica claro que o papel desse mercado é substancialmente reduzido e que, portanto, trata-se de um setor voltado principalmente para o mercado interno. De fato, a demanda doméstica por software no Brasil se aproxima da demanda apresentada por importantes usuários de software internacionais, não só em quantidade como também em complexidade e sofisticação (Botelho et al., 2005). Por um lado, o próprio governo é um importante usuário de sistemas de informação, devido às necessidades de processamento de dados em grandes volumes para o funcionamento dos serviços públicos. Por outro, setores-chave do país proporcionaram a demanda necessária para o desenvolvimento de soluções em software, destacando-se o setor financeiro e de telecomunicações.

\subsection{Evolução do setor}

O processo de surgimento e consolidação da indústria de software brasileira pode ser dividido em três fases distintas do ponto de vista regulatório. Em um primeiro momento, a partir dos anos 1970, o governo executou políticas protecionistas focadas na indústria de hardware, que impactaram o software principalmente de maneira indireta, no que é referido como a fase da reserva de mercado. Entre a liberalização dos anos 1990 e os primeiros anos do novo milênio, o mercado foi aberto para a competição externa e novas frentes regulatórias foram promovidas, com destaque para a Lei de Informática de 1991 e o programa SOFTEX de 1993, mas o software continuou como objetivo secundário e indireto da pauta de políticas industriais. Foi só a partir de 2003, quando a indústria já se encontrava consolidada e possuía tamanho comparável às de outros países emergentes, como a Índia e a China, que o software entrou deliberadamente como atividade estratégica na formulação de políticas industriais.

Mesmo antes da instituição da reserva de mercado para equipamentos de hardware nos anos 1970, grandes usuários de computadores no Brasil já haviam estabelecido o desenvolvimento de software internamente, principalmente o governo e o setor financeiro (Botelho et al., 2005). Com o advento das práticas protecionistas, o software passou a ser considerado uma atividade complementar ao desenvolvimento de hardware, experimentando regras de proteção que eram uma extensão da política adotada para a indústria de computadores (Roselino, 2006). Procurava-se promover o desenvolvimento local das competências em TICs, protegendo as empresas nacionais das importações diretas e da competição com as líderes mundiais da indústria (Tigre e Botelho, 2001).

Os primeiros anos da década de 1990 foram marcados pelo fim das políticas protecionistas e a adoção de um modelo neoliberal, pautado pela abertura comercial, a desregulamentação dos mercados e um menor intervencionismo estatal. A indústria de software e serviços de TI já alcançava nesse momento um faturamento de US\$1,4 bilhões e contava com 6.000 firmas de software (aproximadamente oito vezes mais do que na Índia), enquanto o consumo do governo representava em torno de $25 \%$ do mercado (Schware, 1992). Nesse período de liberalização, as duas políticas que mais se destacaram para o setor de software foram a nova Lei de Informática e o programa SOFTEX, discutidas na subseção 4.2.2.

De maneira geral, a introdução de novas tecnologias de sistemas de informação, a estabilidade econômica advinda do Plano Real de 1994, a queda nos preços de hardware e o surgimento da Internet contribuíram para o desenvolvimento da indústria doméstica de software nos anos 90 . Novas competências 
foram criadas no setor, enquanto firmas já estabelecidas aperfeiçoaram suas habilidades gerenciais a fim de sobreviver no mercado mais competitivo (Botelho et al., 2005).

A indústria de software brasileira desenvolveu um conjunto regionalmente fragmentado de firmas, majoritariamente de pequeno porte (Veloso et al., 2003; Roselino, 2006). O ambiente protecionista, ainda que capaz de promover a criação de competências tecnológicas internas, não incentivava o desenvolvimento das capacidades gerenciais e organizacionais das firmas, já que amenizava seus custos em um contexto de ampla demanda interna (Botelho et al., 2005). Mesmo após a liberalização, essas firmas continuaram a apresentar frágeis competências gerenciais e de organização, em contraste à recém-instalada competição externa. Assim, na evolução do setor de software brasileiro, predominaram entre as firmas domésticas estruturas empresariais frágeis (Roselino, 2006), o que levou, entre outras coisas, a uma baixa representatividade institucional da indústria (Veloso et al., 2003).

Ao longo de toda evolução da indústria de software brasileira, a demanda interna exerceu papel central na criação de competências e especializações no setor. Destacam-se alguns setores-chaves da economia como viabilizadores desta demanda e desenvolvimento. As crises financeiras experimentadas pelo país resultaram, por exemplo, na geração de instituições de alta performance no setor financeiro, que por sua vez tornaram-se tanto usuárias como desenvolvedoras de soluções de software, fundamentais para seu sucesso. É o caso, também, do setor de telecomunicação, desenvolvido domesticamente nos anos 1970 e 80 com significativa criação de competências tecnológicas e de pesquisa, incluindo o Centro de Pesquisa e Desenvolvimento em Telecomunicações (CPqD) em 1976.

O setor público tem um peso considerável como demandante de soluções de software no Brasil. Com efeito, a já mencionada necessidade de processamento de dados, que no caso de um país com dimensões continentais é ainda maior e mais complexa, faz do governo um potencial e importante usuário de software. Apesar dos elevados gastos do setor público com a aquisição de software, critica-se o foco de tais aquisições em fornecedores públicos e a concentração de demandas de menor valor agregado junto ao setor privado, o que limitaria a difusão das competências em software das empresas públicas para o resto do setor (Roselino, 2006).

A liberalização e as transformações tecnológicas da década de 1990 alteraram também a estrutura de financiamento da indústria de software brasileira. O financiamento por capital próprio deu lugar a diferentes tipos de recursos externos à firma, principalmente capital de risco privado e público (Botelho et al., 2005). Em 2000, foi criada a Associação Brasileira de Private Equity e Venture Capital (ABVCAP), contando com o apoio da Financiadora de Estudos e Projetos (FINEP). Os investimentos realizados para o setor de TI a partir da associação chegaram a mais de R $\$ 1.5$ bilhão em 2014, representando $12 \%$ do total (ABVCAP, 2017). A participação do setor, entretanto, oscila significativamente, tendo somado apenas $1 \%$ em 2013, por exemplo.

O Brasil entrou no século XXI com uma indústria de software robusta para os padrões dos países emergentes. O México, por exemplo, cujo PIB per capita em 2001 era 50\% maior do que o brasileiro, apresentava no período um setor de software substancialmente menor, mesmo com a presença do país no North Atlantic Free Trade Agreement (NAFTA) e sua proximidade ao mercado norte-americano (Veloso et al., 2003). De fato, a indústria de software brasileira no período, comparável com a da Índia, Irlanda, China e Coreia do Sul, mostrava fortes sinais de avanço.

\subsection{Elementos-chave do sistema setorial}

\subsubsection{Agentes}

O mercado de software brasileiro apresenta um número elevado de firmas, principalmente de pequeno e médio porte, e concentradas geograficamente. A região Sudeste responde por quase $60 \%$ das firmas de software, e a região Sul por mais de 20\% (Botelho et al., 2005; Bertoni, 2014). Além da quantidade de empresas, concentra-se também nessas regiões a receita líquida e a mão-de-obra empregada na indústria. Já o Distrito Federal, apesar de representar um baixo percentual do número de empresas, tem um peso relativamente alto na receita líquida total da indústria, devido à concentração de empresas públicas 
voltadas principalmente ao desenvolvimento de serviços de informática para o governo federal (Roselino, 2006).

Outra característica essencial da indústria de software brasileira é o predomínio de microempresas. As firmas domésticas de software surgiram historicamente de maneira fragmentada, e, no início dos anos 2000, 86\% destas ainda contavam com quatro ou menos pessoas ocupadas (Roselino, 2006). O ambiente de proteção governamental dos anos 1970 e 80, somado à alta demanda interna, levou a uma configuração empresarial onde pouca atenção era dada a processos de gestão e melhorias de eficiência (Botelho et al., 2005). Mesmo após o processo de liberalização dos anos 1990, entretanto, a estrutura empresarial do setor continuou a concentrar micro e pequenas empresas. De acordo com a ABES (2017), em 2016 quase 50\% do mercado era formado por firmas com menos de dez funcionários, e outros $46 \%$ não teriam mais do que 100 empregados. Esse fenômeno indica uma frágil estrutura empresarial, e reflete práticas que inflam artificialmente o número de empresas do setor, como a contratação de Pessoa Jurídica (PJ) como alternativa à contratação via CLT.

É possível identificar também uma participação expressiva de firmas estrangeiras no mercado de software brasileiro, ainda que minoritária. Estas firmas se concentram nos segmentos mais intensivos em tecnologia e conhecimento, o que indica a maior pressão competitiva a que estão sujeitas as empresas nacionais atuantes nestes mercados.

Ainda que as atividades de baixo valor agregado sejam concentradas em grande parte nas empresas privadas nacionais, é importante destacar a participação expressiva também dessas firmas nos segmentos de serviços em software de alto valor agregado e de software produto. Essas atividades já envolvem etapas mais complexas do processo produtivo do software, incluindo-se as funções relativas à engenharia de software (design de alto nível e análise de sistemas, por exemplo).

Um importante agente do setor de software no Brasil é a Sociedade SOFTEX, uma Organização da Sociedade Civil de Interesse Público (OSCIP) criada em 1996, cujo objetivo é gerir o programa SOFTEX instituído em 1993 (discutido na seção 4.2.2). Junto aos seus agentes regionais, a sociedade forma o chamado Sistema SOFTEX, ao qual se vinculam mais de 2.000 empresas com atividades em software e serviços de TI (SOFTEX, 2012).

A Sociedade SOFTEX atua em importantes frentes para o desenvolvimento do setor de software brasileiro. Entre seus objetivos e atribuições, a organização apoia atividades de inovação tecnológica, promove a estrutura competitiva a partir do Programa SOFTEX de Alianças Empresariais (PAEMPSOFTEX), orienta firmas quanto às fontes de capital e financiamento adequadas, promove a qualificação das firmas a partir do programa de Melhoria de Processo do Software Brasileiro (MPS.BR), atua em iniciativas de ensino como treinamentos, seminários e cursos de pós-graduação, e serve como intermediária nas interações entre indústria, centros acadêmicos e governo.

A organização é responsável também pela gestão de programas ligados ao setor de software e serviços de TI ao nível nacional. Exemplos incluem o Brasil Mais TI, projeto de capacitação gratuita à distância, e o Start-Up Brasil, programa de aceleração de startups criado em 2012. Outra competência importante é a análise e coleta de dados sobre a atividade de software no país, a partir do Observatório SOFTEX, unidade de pesquisa e estudo da Sociedade SOFTEX.

\subsubsection{Políticas públicas}

Ainda na década de 1970, o regime militar inaugura as políticas de fomento às indústrias das TICs com a criação em 1972 da Comissão de Coordenação das Atividades de Processamento Eletrônico (CAPRE). Além de incluir a indústria de informática na pauta de estratégias nacionais, um esforço inicial de capacitação tecnológica em sistemas de informação foi realizado em 1974, com a criação da COBRA (Computadores e Sistemas Brasileiros Ltda.), primeira empresa brasileira a desenvolver, fabricar e comercializar computadores (Diegues et al., 2014). 
Nesse período, o Brasil não adotava mecanismos para proteção da propriedade intelectual nas atividades de software, sob a argumentação de que isso aceleraria a remessa financeira ao exterior e seria um obstáculo ao desenvolvimento do setor. Em concordância a essa visão, um ato normativo de 1975 restringia a importação de software a contratos de transferência tecnológica e à aprovação do Instituo Nacional de Proteção Intelectual (INPI). A partir de 1982, a Secretaria Especial para Informática (SEI) procurou controlar a oferta de produtos internacionais, a partir da criação de um registro de programas computacionais. Em 1983, a produção de microcomputadores em território nacional foi condicionada à adoção de sistemas operacionais desenvolvidos no Brasil.

Essas estratégias, adotadas para a proteção do mercado de equipamentos de hardware, foram consolidadas na Lei de Informática de 1984. Finalmente, em 1987, a comercialização interna do software passou a ser condicionada ao registro junto à SEI, assim como à prova sistemática da inexistência de produtos domésticos similares, política que ficou conhecida como a proteção ao similar nacional (Gaio, 1992).

Em geral, tais políticas protecionistas tiveram impacto limitado na promoção do desenvolvimento doméstico de software. Em primeiro lugar, a característica imaterial e reprodutível do software impossibilita a restrição eficaz de produtos estrangeiros, devido às facilidades de criação e distribuição de cópias ilegais (Roselino, 2006). Além disso, é argumentado por Tápia (1995) que as políticas de proteção não foram devidamente acompanhadas de incentivos e financiamentos para a produção de software nacional, como o apoio a atividades de $\mathrm{P} \& \mathrm{D}$ e o suporte à infraestrutura de $\mathrm{C} \& \mathrm{~T}$, sendo excessivamente passivas no esforço desenvolvimentista.

As deficiências da política protecionista destacadas por alguns especialistas contribuíram para o encarecimento dos produtos de TI, retardando sua adoção no Brasil, bem como para as dificuldades do setor de acompanhar as transformações tecnológicas observadas nos sistemas de informação ao longo dos anos 1980 (Botelho et al., 2005). Entretanto, as competências criadas no período foram fundamentais para o surgimento e a consolidação da indústria de software brasileira. As políticas possibilitaram a expansão de uma base de profissionais em ciência da computação e áreas relacionadas, e contribuíram também para o surgimento de mercados de nicho altamente especializados, como o bancário e o de telecomunicações, dois fatores que seriam importantes para o subsequente desenvolvimento do software no país (Botelho et al., 2005).

A transição para o modelo neoliberal da década de 1990 trouxe mudanças significativas às políticas do país. A intensa liberalização da importação e a entrada de novos concorrentes no mercado significou a emergência de novas oportunidades e restrições. A Lei de Informática, aprovada em 1991 e regulamentada em 1993, substituiu o aparato protecionista pelos incentivos fiscais voltados às empresas de hardware (em sua maioria transnacionais), condicionados ao investimento de 5\% das receitas em atividades de P\&D. Mesmo focadas na indústria de equipamentos de informática, a medida beneficiou firmas de software indiretamente, e estima-se que $25 \%$ dos respectivos fundos de $\mathrm{P} \& \mathrm{D}$ tenha sido gasto no desenvolvimento de software entre 1993 e 2001 (Botelho et al., 2005). A nova política atraiu para o país atividades tecnológicas menos nobres de empresas estrangeiras de TI e permitiu a criação e manutenção de departamentos, laboratórios e institutos de pesquisa. Destaca-se, entretanto, que poucas ligações foram feitas entre essas competências externas e a economia interna, seja com firmas nacionais ou institutos acadêmicos (Roselino, 2006).

O programa SOFTEX, por sua vez, foi a primeira política concebida exclusivamente para o fomento da atividade de software no Brasil, ainda em 1993. Sua concepção, entretanto, deu-se em torno da visão limitada de se emular as experiências internacionais de desenvolvimento de software voltado à exportação. Sua ambiciosa meta inicial seria conquistar $1 \%$ do mercado internacional até o ano 2000, fatia correspondente a aproximadamente US\$ 2 bilhões (Roselino, 2006). Os resultados do programa ficaram bem aquém dos objetivos fixados para o mercado externo, dado que a exportação do software brasileiro em 2001 é estimada em modestos US\$ 100 milhões. Ainda assim, o programa SOFTEX pode ser considerado um marco institucional na indústria de software brasileira, com importantes impactos no mercado interno. Em 2000, as firmas associadas ao programa somavam $41 \%$ do total de firmas de software no Brasil, e 
apresentavam significativa participação na comercialização e geração de emprego do setor (Stefanuto, 2004).

\subsubsection{Demanda doméstica}

Alguns setores domésticos da economia brasileira, dependentes de tecnologia e conhecimento em software, apresentaram excepcional desenvolvimento nos anos 1980 e 1990 . A demanda gerada por esses setores, em geral mais sofisticada do que de outras áreas da economia, foram fundamentais para a criação de competências em software no Brasil. É o caso dos setores bancário e de telecomunicações.

No caso do setor bancário, o Brasil foi capaz de produzir instituições de alto nível a partir de suas experiências e períodos de crise. Com efeito, as instituições nacionais, em contraste com a de outros países emergentes, demonstraram maior performance em indicadores operacionais do setor em relação às firmas estrangeiras, em seguida à abertura do mercado nos anos 90.

O sistema bancário foi um dos principais investidores em TICs no Brasil, respondendo por 30\% dos gastos nos setores relacionados (Botelho et al., 2005). Um exemplo importante de incentivo para a criação de competências em software é a implementação do Sistema de Pagamentos Brasileiro (SPB), sistema complexo que integra governo, bancos e outros agentes, e possibilita a execução de transações e o controle de reservas em tempo real. Estima-se que mais de R $\$ 1,7$ bilhões tenham sido gastos por instituições bancárias para adaptar suas infraestruturas tecnológicas para o SPB. Destaca-se também que as soluções contratadas, inclusive para instituições estrangeiras, foram majoritariamente soluções domésticas (Botelho et al., 2005).

O setor de telecomunicações experimentou um expressivo esforço de criação de competências tecnológicas ao longo dos anos 1970 e 80, centrado no monopólio estatal da Telebrás e na proteção à indústria nacional. A abertura econômica dos anos 1990 diminuiu consideravelmente a participação do capital doméstico no setor, mas os incentivos às atividades de $\mathrm{P} \& \mathrm{D}$ da Lei de Informática garantiu parcialmente a continuidade dos investimentos em competências tecnológicas. Firmas de software do setor de telecomunicações apresentavam indicadores bastante avançados em relação à intensidade de seus processos produtivos em conhecimento e P\&D nos primeiros anos do século XXI (Botelho et al., 2005).

Esse processo de criação de competências se inicia na década de 1970 com o desenvolvimento de software embarcado, em especial na filial local da alemã Siemens. Outras estrangeiras, como a Ericsson, Motorola e Alcatel fixaram-se no país e desenvolveram programas de P\&D em TICs, inclusive no software (Botelho et al., 2005).

O governo responde em grande medida pela demanda interna de software no Brasil. Essa demanda resultou, por exemplo, na criação ainda em 1964 do Serviço Federal de Processamento de Dados (Serpro), empresa pública que mesmo hoje é a maior do país em serviços de TI, e da Companhia de Processamento de Dados do Estado de São Paulo (Prodesp) em 1969, que ainda exerce atualmente as atividades processamento informacional no estado.

\subsection{Dinâmica, mercado interno e inserção externa}

O Brasil apresenta hoje vantagens importantes para a inserção externa no setor de software, a partir da atração de investimentos em P\&D estrangeiros e da implementação de etapas de outsourcing globais em território nacional, e pode se beneficiar das tendências de internacionalização presentes no mercado hoje. Dessas vantagens destacam-se a existência de uma indústria consolidada e com competências de gestão de projetos, a existência de boa infraestrutura de telecomunicações, o baixo custo da mão-de-obra (quando comparado aos países centrais) e o nível de produtividade relativamente elevado (Roselino e Diegues, 2009).

A concorrência no mercado externo, entretanto, seja para a recepção de investimentos de P\&D ou para a inserção em processos de outsourcing, é bastante acirrada, em especial com países já consolidados, como a Índia e a Irlanda. Além de características específicas e não emuláveis desses países não encontradas 
no Brasil, o país teria que resolver importantes obstáculos ao desenvolvimento do setor, como a escassez de mão-de-obra.

É importante mencionar que no início dos anos 2000 foram lançadas novas políticas industriais e de inovação no Brasil, nas quais o setor de software se constituiu como uma das prioridades. Os maiores objetivos destas políticas eram aumentar a competitividade e melhorar a inserção externa das empresas de software. A Política Industrial, Tecnológica e de Comércio Exterior (PITCE) de 2003 incluiu o software como "opção estratégica", junto aos semicondutores, fármacos e bens de capital. Seguiram-se a Política de Desenvolvimento Produto (PDP) em 2008, criada como resposta às limitações da PITCE, e o Plano Brasil Maior de 2011, que continuou a priorizar o software, apesar de expandir significativamente a gama de setores abrangidos. Ao comparar o discurso de cada uma dessas políticas e o financiamento realmente realizado em cada setor (pelo BNDES e pela FINEP), Teixeira, Rapini e Szapiro (2017) verificaram importantes contradições. O setor de software, entretanto, apresentou-se como um dos poucos pontos de coerência entre o discurso e a prática das políticas, recebendo recursos compatíveis com o discurso oficial das políticas.

\section{Análise comparada dos SSI em software na Índia e no Brasil}

Este trabalho apresentou os sistemas setoriais de inovação em software do Brasil e da Índia. Cada SSI encerra trajetórias e elementos-chave específicos, alguns tão idiossincráticos que sua reprodução não é factível, e outros que podem servir de aprendizado para demais países emergentes. A seguir, o artigo analisa as principais diferenças entre os dois modelos, destacando em especial: 1) a natureza da demanda como fonte de conhecimento, 2) o timing, a intensidade e o escopo das políticas públicas, e 3) os diferentes modelos de negócio, processos de gestão e níveis de visibilidade.

Uma das principais diferenças entre o SSI em software indiano e brasileiro está na origem das competências adquiridas por cada um deles. A Índia se beneficia de demanda externa, enquanto o Brasil sustenta sua indústria na sofisticada e diversificada demanda de alguns setores-chave domésticos.

A Índia conta com qualificações particulares que a possibilitaram alcançar a liderança mundial na exportação de serviços de software a partir de 2005, posição que é mantida até hoje. Em especial, destacase a ampla disponibilidade de mão-de-obra indiana qualificada de língua inglesa para os setores de TI, oferta que o Brasil não pôde suprir historicamente. A proximidade horária e, parcialmente, cultural entre os EUA e a Índia também beneficiou o posicionamento internacional do software indiano. A diáspora e do empreendedorismo dos indianos desdobrados no Vale do Silício resultaram em importantes gatekeepers para as firmas de software da Índia, além de terem servido como fonte de capital de risco. As relações firmadas com usuários internacionais de software eram reforçadas com o tempo e a contratação de novos serviços. Dessa forma, competências criadas nos anos 1980 e 90 foram importantes em um contexto de transformações da indústria mundial de software, com a necessidades de se manter sistemas obsoletos e de converter sistemas computacionais para novas tecnologias. Além disso, soma-se fenômenos globais que tiveram impacto positivo para o software indiano, como o intenso processo de outsourcing norte-americano, o problema $\mathrm{Y} 2 \mathrm{~K}$ e as consequências da crise das dotcom.

O Brasil apresenta uma estrutura de demanda de software radicalmente diferente da Índia. Sem dispor dos links e complementariedades específicas que auxiliaram a Índia a alcançar a liderança na exportação de software, o Brasil usufruiu do seu amplo e sofisticado mercado interno, cuja demanda é comparável com a dos principais usuários de software no mundo. As competências do setor no Brasil, portanto, concentraram-se em certos domínios de conhecimento, principalmente bancário, de telecomunicações e de serviços governamentais. O governo consolidou-se em um importante demandante de serviços e produtos de software, diante da necessidade de processar níveis elevados de dados. O sistema financeiro, cuja resiliência foi continuamente reforçada a partir das crises enfrentadas nos anos 1980 e 90, foi também um driver substancial do setor de software, exemplificado no robusto Sistema de Pagamentos Brasileiro (SPB). O setor de telecomunicações, principalmente no período anterior à liberalização e 
privatização dos anos 1990, foi fundamental ao desenvolvimento de capacidades domésticas em atividades de software.

Em segundo lugar, pode-se dizer que, em parte, as trajetórias de políticas públicas voltadas às TICs na Índia e no Brasil apresentam uma evolução similar. Ambos os países iniciaram seus esforços de política focados no protecionismo aos equipamentos eletrônicos e de informática, e adotaram políticas mais liberais a partir dos anos 1990, em certa medida já identificando o software como uma atividade destacada da indústria de TIC.

Entretanto, importantes distinções em termos de política pública são evidentes entre os dois países. A Índia apresentou políticas mais ativas e específicas ao software, adotadas anteriormente em relação ao Brasil. O governo indiano percebeu a importância estratégica do software em 1986, quando passou a definir estratégias do setor independentes da indústria de hardware. Em 1988, a implementação dos Software Technology Parks (STPs) já demonstra a busca ativa da Índia em explorar suas vantagens na exportação de serviços de software. Ademais, em 1992, já no contexto da liberalização econômica, o governo indiano ampliou o incentivo para as atividades de software ao diminuir os impostos para a importação em certos segmentos.

Outra diferença em relação ao Brasil é que a Índia identificou tanto suas vantagens iniciais no setor mundial de software quanto a necessidade posterior de buscar ocupar posições em segmentos de maior valor agregado nas cadeias de valor. O governo foi capaz de implementar instrumentos adequados para tais objetivos e, dessa forma o país pôde manter sua liderança e performance em uma atividade dinâmica e intensiva em conhecimento.

O Brasil implementou algumas iniciativas voltadas à indústria ainda na década de 1980, principalmente focadas na reserva de mercado para softwares produzidos no país. Posteriormente, no início da década de 1990 a liberalização comercial promoveu a entrada de produtos e empresas estrangeiras. Em paralelo, a Lei de Informática implementada em 1991 promoveu atividades de P\&D na indústria de TI, ainda que de forma limitada. Neste mesmo período, a criação do SOFTEX indicou um primeiro passo na política voltada especificamente ao software.

No entanto, todas estas iniciativas podem ser interpretadas como medidas passivas, onde o setor de software não se constituía no foco central da política. É somente a partir de 2004, com a implementação da PITCE que o governo passou a atribuir prioridade ao incentivo do setor de software. Entretanto, mesmo atribuindo prioridade aos incentivos para estimular o setor de software, as políticas praticadas no Brasil a partir da década de 1990 (como o próprio programa SOFTEX, a PITCE, a PDP e o Plano Brasil Maior) buscavam em geral reproduzir experiências bem-sucedidas de outros países, seja a partir do foco no desenvolvimento de software produto, como nos EUA, seja no foco na exportação de software, como na Índia, Irlanda e Israel.

Em terceiro lugar, a análise dos SSI em software na Índia e no Brasil evidencia o diferencial relacionado aos mercados-alvo, aos modelos de negócio e à receita das empresas dos dois países. O modelo indiano favorece naturalmente os serviços de software, enquanto o brasileiro apresenta um espaço expressivo para o desenvolvimento de software produto.

Serviços são intensivos em fator trabalho, necessitam de um menor investimento inicial e, portanto, apresentam um baixo perfil de risco. O segmento oferece, entretanto, uma baixa oportunidade de diferenciação e uma dificuldade de crescimento após determinada escala. Já o software produto requer maior investimento, tanto em desenvolvimento quanto em marketing e suporte, mas em contrapartida apresenta grande retorno no caso de sucesso comercial. O êxito inicial das firmas indianas em serviços de software gerou um efeito manada, com firmas buscando espaços no segmento e fugindo das atividades de produto. No Brasil, onde existe maior participação do software produto na indústria, o desafio de gerar renda neste segmento levou à adoção por muitas firmas de serviços (principalmente customização de software para clientes específicos) como uma fonte secundária de receita.

Como apontado anteriormente, a proximidade de firmas indianas a usuários internacionais de software com demandas e requisitos sofisticados de processos gerenciais e organizacionais possibilitou a 
existência de processos de variabilidade e seleção. O resultado foi uma estrutura empresarial que nasceu ligada às "melhores práticas" da atividade e próxima dos padrões exigidos para a competição no mercado internacional. Assim, hoje as firmas indianas contam com níveis elevados de certificação de qualidade internacional, como o Capability Maturity Model (CMM), em parte devido à sofisticação da estrutura empresarial, com firmas de grande porte que empregam um número elevado de profissionais e geram receitas relativamente altas.

As firmas brasileiras, por outro lado, surgiram de maneira fragmentada, com um número significativo de micro e pequenas empresas, sob um contexto de proteção e alta demanda. Essa situação levou ao desenvolvimento de competências técnicas, por um lado, mas também à baixa sofisticação dos processos de gestão.

Nesta linha, o papel que a associação industrial indiana desempenhou na criação de uma imagem internacional da indústria de software do país foi central. A NASSCOM incentivou a participação de firmas indianas em exibições globais de TI, facilitou o processo de concessão de visto de profissionais indianos para países desenvolvidos, criou iniciativas antipirataria, principalmente para reparar os efeitos negativos das vendas de cópias ilegais nas relações comerciais entre Índia e EUA, entre outras atuações importantes (Joseph, 2009). O esforço resultou em uma visibilidade e projeção positiva da imagem da indústria de software indiana. A ausência de um esforço similar no Brasil não tem contribuído para melhorar a inserção externa do setor.

A Tabela 5.1 a seguir destaca as diferenças principais entre os dois SSI.

Tabela 5.1: Comparação dos SSI em software no Brasil e na Índia

\begin{tabular}{|c|c|c|c|}
\hline \multicolumn{2}{|l|}{ Dimensão } & \multicolumn{2}{|c|}{ Índia $\quad$ Brasil } \\
\hline Demanda & Natureza & $\begin{array}{l}\text { Externa, originada principalmente } \\
\text { no processo de outsourcing norte- } \\
\text { americano }\end{array}$ & $\begin{array}{l}\text { Interna, ancorada em setores-chave, } \\
\text { principalmente bancário e de } \\
\text { telecomunicações }\end{array}$ \\
\hline \multirow[t]{3}{*}{ Política } & Timing & 1980 & 1990, setor estratégico em 2003 \\
\hline & Intensidade & Forte & Fraca \\
\hline & Escopo & $\begin{array}{l}\text { Ativa, focada nas vantagens } \\
\text { (exportação) }\end{array}$ & Passiva, cópia de modelos exportadores \\
\hline \multirow[t]{3}{*}{ Agentes de mercado } & Modelos de negócio & Exportação de serviços & $\begin{array}{l}\text { Software produto para o mercado } \\
\text { interno, renda adicional em serviços }\end{array}$ \\
\hline & Processos de gestão & $\begin{array}{l}\text { Bem desenvolvidos, proximidade } \\
\text { de firmas médias e grandes com } \\
\text { clientes internacionais líderes }\end{array}$ & $\begin{array}{l}\text { Pouco desenvolvidos, firmas de } \\
\text { pequeno e médio porte em contexto de } \\
\text { forte demanda e proteção }\end{array}$ \\
\hline & Visibilidade & Forte (NASSCOM) & Fraca \\
\hline
\end{tabular}

\section{Reflexões finais pensando no Brasil}

O Brasil tem uma das principais indústrias de software, tanto entre países emergentes quanto a nível global. Em contraste com o modelo dos "três Is", focado na inserção externa como porta de entrada para a indústria, o SSI em software brasileiro foi ancorado na sua sofisticada demanda interna, cujo tamanho e complexidade guiaram o processo de aprendizado e crescimento das firmas domésticas.

Este artigo apresentou a trajetória do SSI brasileiro em torno do software vis a vis o caso indiano, a fim de tentar identificar fatores importantes que possam contribuir para a reflexão sobre possíveis caminhos para o desenvolvimento da atividade de software no Brasil. 
O caso indiano tem particularidades históricas, em especial ligadas à inserção de sua diáspora, ao recente alinhamento e complementação com o mercado americano e ao tamanho de sua população e mão de obra qualificada que não são facilmente reprodutíveis em outros países emergentes. Destaca-se também que cada experiência tem seus pontos fracos e margem de aprimoramento. No caso indiano, apesar da boa performance exportadora, o SSI em software é muito concentrado tanto ao interior da Índia, principalmente em torno a Bangalore, como em relação aos mercados de destino, principalmente os EUA. Da mesma forma, o baixo desenvolvimento do software produto e os baixos links com a estrutura produtiva interna ainda se apresentam como um desafio para SSI da Índia.

O Brasil apresenta dificuldades na competição internacional em torno das atividades de menor valor agregado (como manutenção de sistemas obsoletos, serviços internos de suporte ou serviços de codificação e testes), uma vez que essas são baseadas principalmente em mão-de-obra de baixo custo, cuja vantagem se encontra em países como a Índia e a China, ou mesmo em especificidades históricas indianas, como a difusão da língua inglesa e a diáspora de profissionais de TI. Entretanto, a própria experiência brasileira já demonstra a importância dos serviços de software para um aumento no faturamento das firmas, e o caso de sucesso da Índia atesta para as vantagens de se desenvolver uma atividade de serviços no setor. A criação de credibilidade e exposição internacional estabelecendo confiança com agentes de mercado externo é essencial para a expansão externa da indústria. $\mathrm{E}$ as exportações têm importantes impactos no balanço de pagamentos e na criação de empregos qualificados.

Neste sentido, uma importante oportunidade para o Brasil seria a inserção internacional em segmentos de serviços com maior valor agregado, em setores verticais onde o software brasileiro desenvolveu competências mais dinâmicas, como o bancário, o de telecomunicações e comércio eletrônico. O simples incentivo para exportação, entretanto, apresenta baixa efetividade, já que a Índia domina o mercado mesmo em segmentos de maior valor agregado. A competição externa, portanto, seria dependente da consolidação de firmas brasileiras nos mercados externos, particularmente aproveitando potenciais complementações no âmbito latino americano e integrações sul-sul.

Em paralelo, as oportunidades oferecidas pelo mercado interno brasileiro deveriam ser exploradas com o objetivo de consolidar firmas nacionais e desenvolver capacitações locais. Considerando a demanda doméstica crescente e a sofisticação moderada de uma grande parcela de clientes, o mercado interno brasileiro deve ser percebido como um ativo competitivo das firmas brasileiras. Vale destacar que o incentivo através de políticas públicas é fundamental para estimular o desenvolvimento de capacitações produtivas e inovativas das firmas brasileiras, viabilizando o melhor aproveitamento das oportunidades abertas no âmbito do mercado interno.

Finalmente, outro aprendizado a partir da experiência indiana é que a performance do setor de software em países emergentes não é resultado apenas da ação governamental, ainda que as políticas públicas sejam essenciais para o sucesso competitivo das firmas nacionais. A combinação de inserção geopolítica, características específicas do sistema de inovação e existência de agentes institucionais empreendedores são essenciais para garantir a capacidade do país em explorar as oportunidades existentes na área de TI.

\section{Referências}

ABES. Mercado Brasileiro de Software: panorama e tendências. $1^{\mathrm{a}}$. ed. São Paulo: Associação Brasileira das Empresas de Software, 2017.

ABVCAP. Consolidação de Dados: Indústria de Private Equity e Venture Capital no Brasil (2011-2016). [S.1]: Associação Brasileira de Private Equity e Venture Capital, 2017.

ASHEIM, B. T.; ISAKEN, A. Location, agglomeration and Innovation: towards regional Innovation systems in Norway? Oslo: STEP group - Studies in Technology, Innovation and Economic Policy, n.13/96. 1996. 
ATHREYE, S. The Indian Software Industry. In: ARORA, A; GAMBARDELLA, A (org). From Underdogs to Tigers: The Rise and Growth of the Software Industry in Brazil, China, Ireland and Israel. Oxford: Oxford University Press, cap. 2, 2005.

BERTONI, Rebeca. Obstáculos à inovação na Indústria Brasileira de Software e Serviços de TI. Dissertação (Mestrado em Desenvolvimento Econômico). Campinas: Instituto de Economia, Universidade Estadual de Campinas, 2014.

BOTELHO, A.; STEFANUTO, G.; VElOSO, F., The Brazilian Software Industry. In: ARORA, A; GAMBARDELLA, A (org). From Underdogs to Tigers: The Rise and Growth of the Software Industry in Brazil, China, Ireland and Israel. Oxford: Oxford University Press, cap. 5, 2005.

BRACZYK, H. J.; COOKE, P.; HEIDENREICH, M. Regional Innovation systems: the role of governances in a globalized world. Londres: Bristol, PA.: UCL Press, 1998.

CARLSSON, B.; STANKIEWITZ, R. On the Nature, Function and Composition of Technological Systems. Journal of Evolutionary Economics, Vol. 1, p. 93-118, 1991.

CASSIOLATO, J. E.; LASTRES, H.; Sistemas de Inovação e Desenvolvimento: as implicações de política. São Paulo em Perspectiva, 2005.

COOKE, P.; URANGA, M. G.; ETXEBARRIA, G. Regional systems of Innovation: institutional and organizational dimensions. Research Policy, v. 26, n.1, p. 475-491, 1997.

DE LA MOTHE, J.; PAQUET, G. Local and regional systems of innovation. Economics of science, technology and innovation. Boston, Mass.: Kluwer Academic Publishers, 1998. v. 14.

DIEGUES, A. C.; ROSElinO, J. E.; GARCIA, R. Política Industrial e Desenvolvimento: o caso da indústria brasileira de Tecnologia de Informação. Espacios, v. 35, n. 12, p. 13, 2014.

DOSI, G.; FREEMAN, C.; NELSON, R.R.; SILVERBERG, G.; SOETE, L. (ed.). Technology and economic theory. Londres: Pinter Publishers, 1988.

D'COSTA, A.P. Uneven and Combined Development: Understanding India's Software Exports. World Development, v. 31, n. 1, p. 211-226, 2003.

EDQUIST, C. (ed.). Systems of innovation: Technologies, institutions and organizations. Londres: Pinter Publishers, 1977.

FREEMAN, C. Technology Policy and Economic Performance: Lessons from Japan. Londres: Frances Pinter, 1987.

GAIO, F. Software Strategies for Developing Countries: Lessons from the Brazilian Experience. In: SCHMITZ, H.; CASSIOLATO, J. High-tech for Industrial Development, Toutledge, Londres, 1992.

GONZALO, M. A long-term narrative on India from Latin America: Peripherization, national system of innovation and autonomous expenditures. Tese de Doutorado. Rio de Janeiro: Instituto de Economia/Universidade Federal do Rio de Janeiro, 2018.

GONZALO, M.; CASSIOLATO, J. Trayectoria histórica de desarrollo del Sistema Nacional de Innovación de India (1947-2017). Márgenes Revista de Economía Política, Año III, n. 3. UNGS, 2017.

GONZALO, M.; KANTIS, H. Venture capital in India: a critical view from an evolutionary and systemic perspective.15th International Globelics Conference, Atenas, 2017.

HEEKS, R. India's Software Industry: State Policy, Liberalization and Industrial Development. Nova Délhi: Sage Publications, 1996. 
JOSEPH, K. J. Sectoralinnovation Systems in Developing Countries: the case of ICT in India. In: LUNDVALL B A, JOSEPH, K. J.; C. CRISTINA; VANG, J. (ed.). Handbook of Innovation Systems and Developing Countries. Cheltenham: Edward Elgar, 2009.

. India's Software Industry in Transition: Lessons for Other Developing Countries and Implications for South-South Cooperation. Productivity Journal, v. 54, n. 4, 2014.

LEE, K.; TAE YOUNG PARK; RISHIKESHA KRISHNAN. Catching-up or Leap frogging in the Indian CIS Sector: Windows of Opportunity, Path-creating, and Moving Up the Value Chain. Development Policy Review, 2013.

LUNDVALL, B-Å. (ed.). National innovation systems: towards a theory of innovation and interactive learning. London: Pinter, 1992.

MALERBA, Franco. Sectoral systems of innovation and production. Research Policy, v. 31, p. 247-264, 2002.

.Sectoral systems of innovation: a framework for linking innovation to the knowledge base, structure and dynamics of sectors. Economics of Innovation and New Technology, v. 14, n. 1-2, p. 63-82, 2005.

NASSCOM. The IT-BPM Sector in India: Strategic Review, 2017. Nova Délhi: NASSCOM, 2017.

NELSON, R.R. (ed.) National Innovation Systems: A Comparative Analysis, Oxford, Oxford. University Press, 1993.

QUINN, J.B.; BARUCH, J.J.; ZIEN, K.A. Innovation Explosion: Using Intellect and Software to Revolutionize Growth Strategies. Free Press, 1997.

ROSELINO, J. E. A Indústria de Software: O 'modelo brasileiro' em perspectiva comparada. Tese (Doutorado em Ciências Econômicas). Campinas: Instituto de Economia, Universidade Estadual de Campinas, 2006.

ROSELINO, J. E.; DIEGUES, A. C. Perspectivas do Investimento em Tecnologias de Informação. Relatório integrante da pesquisa Perspectivas do Investimento no Brasil, 2009.

SCHUMPETER, J. A. Capitalism, Socialism and Democracy. Nova York: Harper \&Row, 1962.

SCHWARE, R. Software industry entry strategies for developing countries. World Development, v. 20, n. 2, p. 143 164, 1992.

SHARIF, N. Dynamics of Industry and Innovation: Organizations, Networks and Systems. DRUID Tenth Anniversary Summer Conference, 2005.

SOFTEX, Observatório. Software e Serviços de TI: A indústria brasileira em perspectiva. Campinas, 2012.

STEFANUTO, G. N. O Programa Softex e a Indústria de Software no Brasil, Tese (Doutorado em Política Científica e Tecnológica). Campinas: Instituto de Geociências, DPCT, UNICAMP, 2004.

TEIXEIRA, A. L.; RAPINI, M. S.; SZAPIRO, M. Discurso e Prática da Política Industrial no período 2005-2014: uma avaliação da distribuição setorial dos recursos reembolsáveis do BNDES e da FINEP. São Paulo: Blucher, 2017.

TIGRE, P.; BOTELHO, A. Brazil Meets the Global Challenge: IT Policy in a Post liberalization Environment. The Information Society: An International Journal, 2001.

TÁPIA, J. B. A trajetória de Política de Informática Brasileira (1977-1991) - Atores, instituições e estratégias. [S.1.]: Editora Papirus, 1995.

VELOSO, F.; BOTELHO, A.; TSCHANG, T. Slicing the knowledge-based economy in Brazil, China and India: a tale of 3 software industries. Massachussetts Institute of Technology (MIT), 2003. 